\title{
Splenic infarction during Plasmodium ovale acute malaria: first case reported
}

\author{
Gaël Cinquetti ${ }^{*}$, Frédéric Banal ${ }^{1}$, Candyce Rondel ${ }^{1}$, David Plancade ${ }^{2}$, Charlotte de Saint Roman $^{3}$, \\ Dina Adriamanantena ${ }^{1}$, Céline Ragot ${ }^{4}$, Serge Védy ${ }^{4}$, Bruno Graffin ${ }^{1}$
}

\begin{abstract}
The splenic complications of acute malaria include two different prognostic and treatment entities: splenic infarction and splenic rupture. This is the first case of splenic infarction during an acute malaria due to Plasmodium ovale in a 34-year-old man. As in the majority other described cases of splenic infarction, the course was spontaneously favourable, suggesting that this complication was relatively benign compared to splenic rupture, which is life-threatening and usually necessitating surgery.
\end{abstract}

\section{Background}

Splenic infarction is a rare complication usually described during acute malaria with Plasmodium falciparum or Plasmodium vivax. Splenic rupture is another, less well-known life-threatening malaria complication. A case of splenic infarction during acute malaria due to Plasmodium ovale is reported. This is the first case described in the literature with this species. This case supplements the splenic complication panel of acute malaria, with two different prognostic and treatment entities: splenic infarction and splenic rupture.

\section{Case report}

A 34-year-old man, a French professional soldier, with no remarkable medical history, had two previous exposures to endemic malaria zones (four months in Senegal in 2002, and four months in Ivory Coast in 2004). He stated having taken his anti-malarial chemoprophylaxis (doxycycline, $200 \mathrm{mg} /$ day) more or less regularly during his stays, having omitted to take the medication on several occasions. He never had acute malaria previously.

In 2008 , he developed a $39,5^{\circ} \mathrm{C}$ fever with headache, asthenia, myalgias, with nausea and vomiting. After a few days of self-treatment with paracetamol, he presented to the Emergency Department at the Military Hospital Legouest, Metz, France. Physical examination

\footnotetext{
* Correspondence: gael.cinquetti@gmail.com

'Service de Médecine Interne et Maladie Infectieuses et Tropicales, Hôpital d'Instruction des Armées Legouest, 27 avenue de Plantières, BP 90001, 57077 METZ Cedex 3, France

Full list of author information is available at the end of the article
}

showed a $14 \mathrm{~cm}$ painless splenomegaly, and a temperature of $39^{\circ} \mathrm{C}$. All other physical findings were normal. Laboratory tests showed anaemia $(\mathrm{Hb} 11.8 \mathrm{~g} / \mathrm{dl})$, thrombocytopaenia (platelets $117 \times 109 / \mathrm{mm} 3$ ), leukopaenia $(3250 / \mathrm{mm} 3)$, lymphocytopaenia $(839 / \mathrm{mm} 3)$ and a moderate increase in liver enzymes (aspartate aminotransferase/alanine aminotransferase were both about twice the upper limit of normal values). The diagnosis of acute malaria was made by blood smear examination, with $0.001 \%$ P. ovale parasitaemia. The species diagnosis was confirmed by molecular biology (polymerase chain reaction), without bi-parasitism (no $P$. falciparum or P. vivax associated).

The patient was admitted and treatment was started with intravenous quinine because of vomiting $(8 \mathrm{mg} / \mathrm{kg}$ three times a day), and was well tolerated. Fever subsided gradually over three days, anaemia resolved without transfusion and signs of hepatic cytolysis disappeared within a few days.

Six days after his admission, the patient complained of a sudden onset of left hypochondrial pain. Physical examination showed persistent, painful and tender splenomegaly. Abdominal CT-scan (Figure 1) showed several splenic infarcted zones, the largest measuring $53 \times$ $37 \mathrm{~mm}$, in the upper pole in the anterior edge, and in the dorsal face as well as in the lower pole.

His haemodynamic status was stable and simple analgesics were effective, obviating the need for emergency surgery. Management consisted only of medical monitoring and analgesia (subcutaneous morphine). 


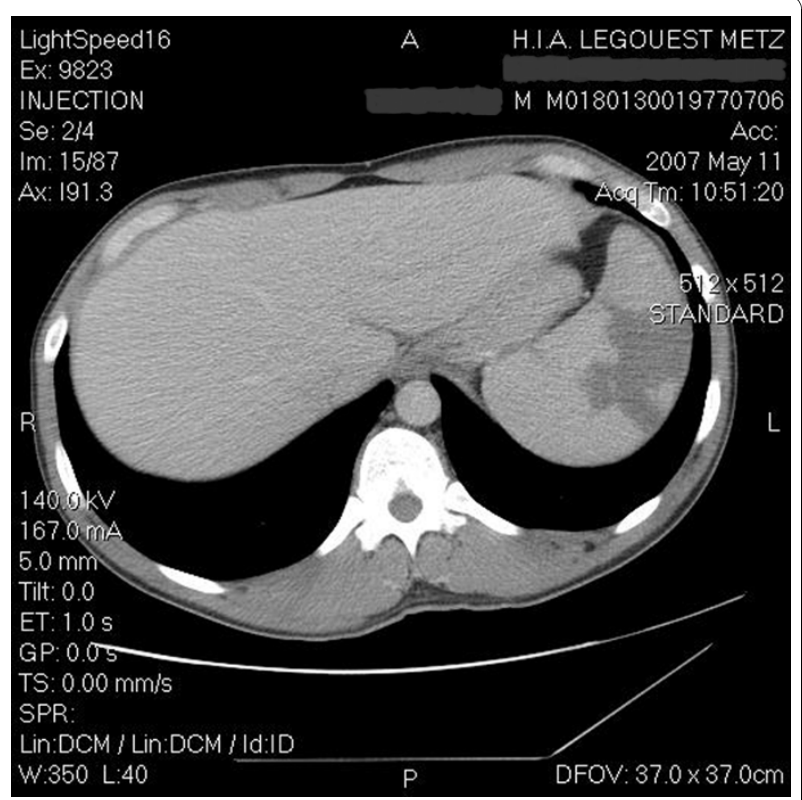

Figure 1 Abdominal CT-scan: splenomegaly and splenic infarction.

The splenic abnormalities regressed spontaneously over several months, during which the patient continued to tire easily. Haemoglobin was $10.6 \mathrm{~g} / \mathrm{dl}$ one month after initial onset. Exploration of other causes of splenic infarction, including constitutional underlying coagulation disorder (C and S-protein, Leyden mutation, homocystein, antithrombin III and antibody antiphospholipid measurement), sickle cell disease (normal haemoglobin electrophoresis) and concomitant Salmonella infection, were negative.

\section{Conclusions}

Malaria is one of the main infectious threats for the French army. Engaged in short-term missions or outside operations, 35,000 to 40,000 French soldiers stay every year in zones of endemic malaria disease. For 10 years, the rate of malaria incidence in the French army has been between 1,9 and 5,8 percent of men annually, and unfortunately, four deaths have been reported.

In 2008, 413 acute malaria cases were declared in the French army. 92,6\% of which were uncomplicated clinical forms. $56.4 \%$ of the cases were due to P. vivax, $36 \%$ to P. falciparum, $1.2 \%$ to Plasmodium malariae and $6.3 \%$ to P.ovale, the frequency of which is on the increase.

Splenic infarction is a rarely described, and probably under-diagnosed, complication of malaria. Bonnard et al [1] found only eight documented cases of splenic infarction associated with malaria in the literature. Two other case reports are described, including a case discovered fortuitously during an autopsy, adding up to a total of ten descriptions. Frequently, they were young patients (3 to 30 years old), all infected with $P$. falciparum (except one case of co-infected with $P$. vivax and one case unknown), without anti-malarial prophylaxis (except one, and two unknown). They all survived with medical treatment (except one surgical treatment). No death due to splenic complications is mentioned.

Rupture of the spleen is more common than splenic infarction during malaria and is a diagnostic emergency, usually necessitating surgery. Pathological rupture of the spleen has rarely been reported following $P$. ovale or $P$. malariae infection. In a recent litterature analysis, Imbert et al [2] found only two cases involving P. ovale. This is a very serious, life-threatening complication, even if the two cases described show that the issue was not always fatal.

Infarction-induced haemorrhage does not consistently fit available pathological data. Haemorrhages have been observed in splenic tissue devoid of signs of infarction, and infarction was noted in only two of 55 spleen rupture cases reported over the last 50 years.

In the 10 cases of splenic infarction reported over the last 30 years, only two cases were complicated by splenic rupture (in a child with a $P$. vivax and in a P. falciparum mixed infection and in an adult suffering from P. vivax malaria) $[3,4]$. For this reason, splenic infarction must be considered as a different complication from splenic rupture in acute malaria, with a very different prognostic and treatment. This complication must be evoked whatever the plasmodial species. As in the majority other described cases, the course was spontaneously favourable, suggesting a relative benignity of this complication.

\section{Consent}

Written informed consent was obtained from the patient for publication of this case report and any accompanying images. A copy of the written consent is available for review by the Editor-in-Chief of this journal.

\section{Acknowledgements}

The authors thank Helen and Olivier Banal for their contributions to the English manuscript.

\section{Author details}

'Service de Médecine Interne et Maladie Infectieuses et Tropicales, Hôpital d'Instruction des Armées Legouest, 27 avenue de Plantières, BP 90001, 57077 METZ Cedex 3, France. ${ }^{2}$ Service de Réanimation, Hôpital d'Instruction des Armées Legouest, 27 avenue de Plantières, BP 90001, 57077 METZ Cedex 3, France. ${ }^{3}$ Service de Chirurgie Viscérale, Hôpital d'Instruction des Armées Legouest, 27 avenue de Plantières, BP 90001, 57077 METZ Cedex 3, France. ${ }^{4}$ Service de Biologie, Hôpital d'Instruction des Armées Legouest, 27 avenue de Plantières, BP 90001, 57077 METZ Cedex 3, France. 


\section{Authors' contributions}

GC, FB and CR wrote the manuscript. DP, CSR, DA, and BG carried out the physical examination. CR and SV carried out the biological analysis. All authors read and approved the final manuscript.

\section{Competing interests}

The authors declare that they have no competing interests.

Received: 1 February 2010 Accepted: 18 October 2010

Published: 18 October 2010

\section{References}

1. Bonnard P, Guiard-Schmid JB, Develoux M, Rozenbaum W, Pialoux G: Splenic infarction during acute malaria. Trans R Soc Trop Med Hyg 2005, 99:82-86.

2. Imbert P, Rapp C, Buffet PA: Pathological rupture of the spleen in malaria: analysis of 55 cases (1958-2008). Travel Med Infect Dis 2009, 7:147-159.

3. Facer CA, Rouse D: Spontaneous splenic rupture due to Plasmodium ovale malaria. Lancet 1991, 338:896.

4. Patel Ml: Spontaneous rupture of a malarial spleen. Med J Aust 1993, 159:836-837.

doi:10.1186/1475-2875-9-288

Cite this article as: Cinquetti et al:: Splenic infarction during Plasmodium ovale acute malaria: first case reported. Malaria Journal 2010 9:288.

\section{Submit your next manuscript to BioMed Central} and take full advantage of:

- Convenient online submission

- Thorough peer review

- No space constraints or color figure charges

- Immediate publication on acceptance

- Inclusion in PubMed, CAS, Scopus and Google Scholar

- Research which is freely available for redistribution

Submit your manuscript at www.biomedcentral.com/submit 